\title{
Inbaltzwerzeichniz.
}

Qlbtürz̆ungen , . . . . . . . . . . . . . . . . V

1. Cinleitung. (Entitehung bes Bejebes, feine wejentlichen Reuerungen 1

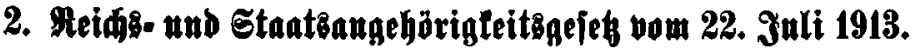

Eriter $\mathfrak{A b j}$ initt.

Mugemeine Borfduxiften.

(\$§ 1 und 2).

§ 1. Begriffsbejtimmung desె Deutjhen . . . . . . . . . 5

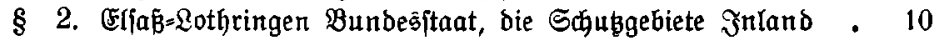

Bweiter $\mathfrak{A} b$ fanitt.

Stanţangebörigfeit in einem Bunbegftaate

(\$8 3 mit 32).

§ 3. Wie wirb bie Staatsangehärigfeit erworben? . . . . . 11

§ 4. Ermerb burd Beburt; Finbelfinber . . . . . . . . 13

§ 5. Ermerb Durd Regitimation. . . . . . . . . . . . 16

$\S$ 6. Erwerb burd Ehejdließ̧ung . . . . . . . . . . . 17

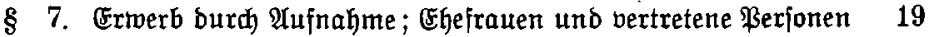

$\S$ 8. Errverb burø Einbürgerung . . . . . . . . . . . 25

$\S 9$. Finvernahme der $\mathfrak{B u n d e s i t a a t e n ~ b e i ~ e i n e r ~ E i n b u ̈ r g e r u n g ~ . ~} 29$

$\$ 10$. Cinbürgerung einer ehemalo beutiden Mitwe ober geidjebenen Frau . . . . . . . . . . . . . . . . 34

§ 11. Wiebereinbürgerung eines ehemaligen Deutiđjen, ber als Minderiägriger entlafien wurde . . . . . . . . . 36

\$ 12. Finbürgerung einer \$erjon, bie attio im \$eere oder in ber Macine gebient hat... . . . . . . . . . . 37

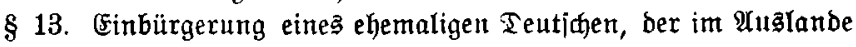
bleibt . . . . . . . . . . . . . . . . . 38

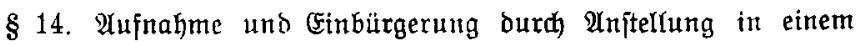
Bundeâftaat . . . . . . . . . . . . . . . . 41

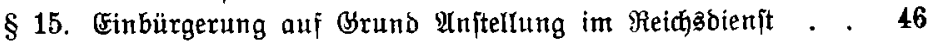




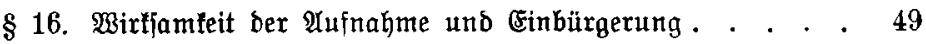

\$ 17. Werluftgründe ber Etaatæangehörigfeit . . . . . . . 52

\$ 18. Entlaffung einex Ehefrau . . . . . . . . . . . . 54

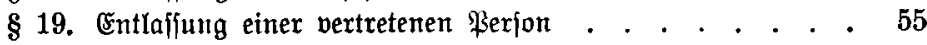

\$ 20. Entrafjung mit ober ohne Borbehalt einer Staaţangehỏrigleit 58

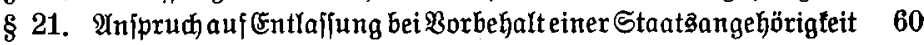

§ 22. Berweigerunģ̨gründe ber Entlajĭung . . . . . . . . 61

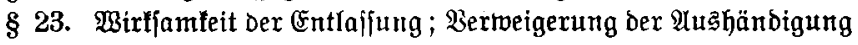
ber Entlaffungsurtunde. . . . . . . . . . . . 62

§ 24. Uufhebung Der \$irfung Der Entlaffung . . . . . . . . 65

§ 25. Berluft burd) Erwerb einer fremben Staatsangehörigleit . 66

\$ 26. Berluft wegen Berlegung ber $\mathfrak{B e h r p f l i c h t}$. . . . . . . . 69

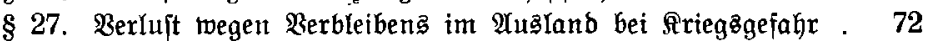

§ 28. Berluft bei Eintritt in fremben Staatosbienft . . . . . . 73

§ 29. Wirkung von ßerlujtgründen auf (shefrau und ßinder. . 75

§ 30. Einbürgerungsanipruch eines ehemaligen Deutichen, ber die Staatzangehörigleit Durch Entlafiung verloren hat . . . 76

\$ 31. (Einbürgerıngsaniprud) eines ehemaligen Deut ljell, ber bie

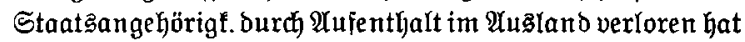

§ 32. Übergang3̄ooriarift bei Berlegung ber Wehrpificht . . Dritter $\mathfrak{A} b[\mathfrak{d})$ nitt.

\section{Unuittelbare Reid)angehörigfeit} (\$\$ 33 mit 35).

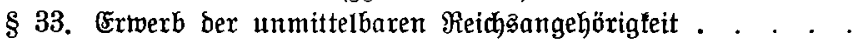

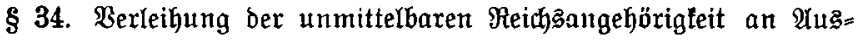

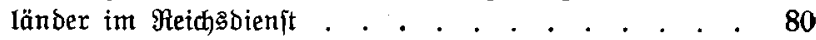

§ 35. Anmendung der Beptimmungen über bie Staaţangehörigfeit in einem $B$ un besftaat auf Die unmittelbare Reidbangeljörigleit

Bierter $\mathfrak{U} b \mathfrak{j}$ nitt.

\section{SळI}

(\$§ 36 mit 41).

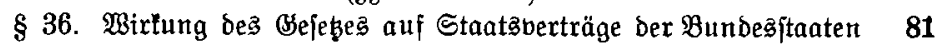

$\S$ 37. Berweifung auf andere Bejebe . . . . . . . . . . 82

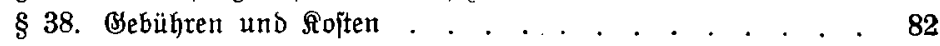

\$39. Bułtändigleit für bie Form ber Urfunden und für die $\mathfrak{B e}=$ ftimmung von behörben . . . . . . . . . . . . . . . 83

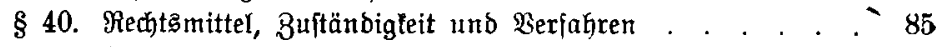

§ 41. Jnfraftreten be马 Befeezes. . . . . . . . . . . . . . . 86

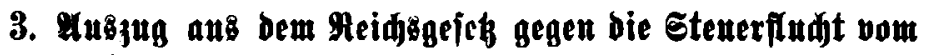

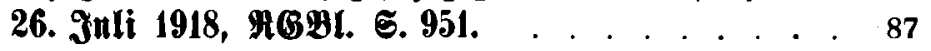




\section{Bollzugavoridiriften.}

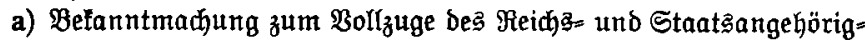
feitâgefęę̧ vom 3. März 1916/16. November 1918 . . . . . 88

Anlagen hierz̆ . . . . . . . . . . . . . . . . . 100

b) Min.=Bet. über Wahlreht uno Staat3angeljörigleit Der vor-

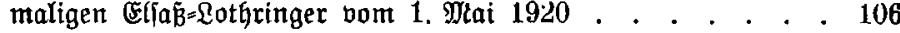

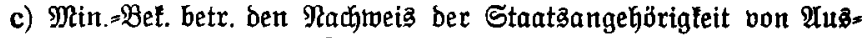
landşbeutiden bon 16. März 192L . . . . . . . . . , 106

d) beşgl. vom 4. Mai 1921 . . . . . . . . . . . . . . . . . . . 107

\section{Xuhang.}

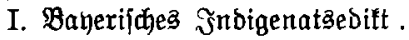

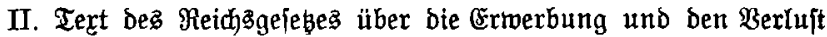

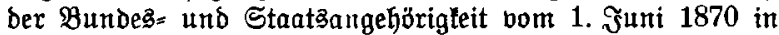

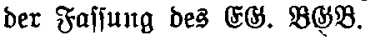

III. Ułberficht über bie wejentlidjiten (Sründe für ben Erwerb und ben Berluf́t ber Staatsangehörigleit in Belgien, Dänemart,

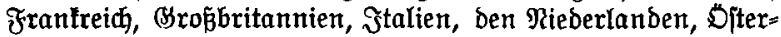

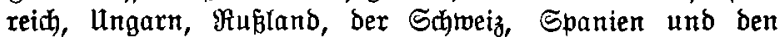
Bereiniglen Staaten bon $\mathfrak{U m e r i f \mathfrak { a }}$. . . . . . . . .

IV. Die auf bie Staatşangehörigfeit bez̈̈̈glichen Bejtimmungen Des Berjailler Diftates nebit $\mathfrak{A} u \not ̧$ führungz̧berträgen und

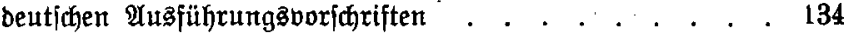

A. Die Beṕtimmungen von Berjailles . . . . . . 134-142

1. Ulrgemeine Bejtimmung . . . . . . . . . . . 135

2. Elja $\tilde{\beta}=$ \&othringen . . . . . . . . . . . . . 135

3. Moreanet, Eupen und Malmedy . . . . . . . . . . 137

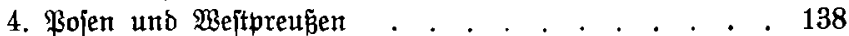

5. Oberichlefien. . . . . . . . . . . . . . . . 139

6. Schlefildhe Grebietsteile . . . . . . . . . . . . 139

7. Roxbjdlesmig . . . . . . . . . . . . . . . 140

8. Memelgebiet. . . . . . . . . . . . . . . 141

9. Danzig . . . . . . . . . . . . . . . . . 141

10. Saarbedengebiet . . . . . . . . . . . . . . 142

11. Sthubgebiete . . . . . . . . . . . . . . . 142

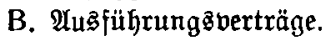

1. Sertrag mit Danzig über Optionżaragen . . . . . . 142

2. Staatsangehörigleitsvertrag mit ber Tiđechoflovalet . . 144

C. $\mathfrak{A} u$ ğ ührungăborjdriftert.

1. Optionşoronung vom 3. Dezember 1921 . . . . . . . 149

2. Min.=Bef. über die Option für Deutidhland ober Bolen bom 17. Dezember 1921 . . . . . . . . . . . 150 